\title{
Conjunctival sac bacterial flora isolated prior to cataract surgery
}

\author{
This article was published in the following Dove Press journal: \\ Infection and Drug Resistance \\ 23 January 2012 \\ Number of times this article has been viewed
}

\author{
Chikako Suto ${ }^{1,2}$ \\ Masahiro Morinaga ${ }^{1,2}$ \\ Tomoko Yagi ${ }^{1,2}$ \\ Chieko Tsuji ${ }^{3}$ \\ Hiroshi Toshida ${ }^{4}$ \\ 'Department of Ophthalmology, \\ Saiseikai Kurihashi Hospital, Saitama; \\ ${ }^{2}$ Department of Ophthalmology, Tokyo \\ Women's Medical University, Tokyo; \\ ${ }^{3}$ Department of Clinical Laboratory, \\ Saiseikai Kurihashi Hospital, Saitama; \\ ${ }^{4}$ Department of Ophthalmology, \\ Juntendo University Shizuoka \\ Hospital, Izunokuni, Shizuoka, Japan
}

Correspondence: Hiroshi Toshida Department of Ophthalmology, Juntendo University Shizuoka Hospital, I I 29 Izunokuni, Shizuoka, 410-2295, Japan $\mathrm{Tel}+8 \mathrm{I} 559483$ III

Fax +8I 55948335

Email toshida@juntendo.ac.jp
Objective: To determine the trends of conjunctival sac bacterial flora isolated from patients prior to cataract surgery.

Subjects and methods: The study comprised 579 patients (579 eyes) who underwent cataract surgery. Specimens were collected by lightly rubbing the inferior palpebral conjunctival sac with a sterile cotton swab 2 weeks before surgery, and then cultured for isolation of bacteria and antimicrobial sensitivity testing. The bacterial isolates and percentage of drug-resistant isolates were compared among age groups and according to whether or not patients had diabetes mellitus, hyperlipidemia, dialysis therapy, oral steroid use, dry eye syndrome, or allergic conjunctivitis.

Results: The bacterial isolation rate was 39.2\%. There were 191 strains of Gram-positive cocci, accounting for the majority of all isolates (67.0\%), among which methicillin-sensitive coagulase-negative staphylococci was the most frequent (127 strains, 44.5\%), followed by methicillin-resistant coagulase-negative staphylococci (37 strains, 12.7\%). All 76 Gram-positive bacillary isolates (26.7\%) were from the genus Corynebacterium. Among the 16 Gram-negative bacillary isolates (5.9\%), the most frequent was Escherichia coli (1.0\%). The bacterial isolation rate was higher in patients $>60$ years old, and was lower in patients with dry eye syndrome, patients under topical treatment for other ocular disorders, and patients with hyperlipidemia. There was no significant difference in bacterial isolation rate with respect to the presence/ absence of diabetes mellitus, steroid therapy, dialysis, or a history of allergic conjunctivitis. Methicillin-resistant coagulase-negative staphylococci showed a significantly higher detection rate in diabetic patients than nondiabetic patients $(20.3 \%$ versus $7.0 \%, P<0.05)$. The percentage of all isolates resistant to levofloxacin, cefmenoxime, and tobramycin was $14.0 \%, 15.2 \%$, and $17.9 \%$, respectively, with no significant differences among these drugs.

Conclusion: The high bacterial isolation rate in patients $>60$ years old and the high methicillinresistant coagulase-negative staphylococci isolation rate in patients with diabetes are important to consider for prevention of perioperative infections.

Keywords: endophthalmitis, cataract surgery, conjunctival sac, bacterial flora, diabetes mellitus

\section{Introduction}

Age-related cataract is responsible for $48 \%$ of world blindness, which represents about 18 million people. ${ }^{1}$ Cataract surgery has become widespread in developed countries thanks to advances in procedures and instruments, and almost all patients achieve recovery of visual acuity as a matter of course after treatment. Further, incidence of endophthalmitis after cataract surgery is decreasing. ${ }^{2}$ However, if postoperative endophthalmitis occurs, there is a high risk of loss of vision with 
consequent adverse effects on the patient's quality of life. At the same time, the responsibility for endophthalmitis is a mental burden for the surgeon.

It has been reported that indigenous bacteria in the conjunctival sac influence the bacterial pathogens causing endophthalmitis after cataract surgery. ${ }^{3}$ It is likely that conjunctival sac bacterial flora would be altered by factors that affect a patient's general condition such as diabetes mellitus, corticosteroid use, and aging. ${ }^{4-8}$ Accordingly, this study was conducted to compare isolates from the conjunctival sac bacterial flora prior to cataract surgery in order to identify differences of isolates and resistance to antimicrobial agents related to patient factors such as the presence/absence of diabetes mellitus, hyperlipidemia, oral steroid therapy, dry eye syndrome requiring topical medication, other ocular conditions except requiring topical antimicrobial agents, and allergic conjunctivitis.

\section{Subjects and methods}

The study population comprised 579 patients (579 eyes) who underwent cataract surgery in the Department of Ophthalmology of Saiseikai Kurihashi Hospital during a 3.5-year period from January 2004 to June 2007. The patients were enrolled in a consecutive manner. All patients provided informed consent, this study was conducted in accordance with the Declaration of Helsinki, and only one eye was investigated even in patients with cataracts affecting both eyes. There were 234 men (40.4\%) and 345 women $(59.6 \%)$ who ranged in age from 51 to 100 years (mean \pm standard deviation: $71.7 \pm 9.5$ years).

Two weeks before cataract surgery, specimens for bacteriologic examination were collected from the conjunctival sac, without anesthesia, by lightly rubbing the inferior palpebral conjunctiva with a sterile cotton swab, and were transferred within 1 hour to the clinical laboratory of the hospital for plating on blood agar medium and chocolate agar medium. ${ }^{9,10}$ Cultures were incubated at $35^{\circ} \mathrm{C}$ for $24-48$ hours. Neither anaerobic nor enrichment cultures were performed. Antimicrobial sensitivity testing of the bacterial isolates was carried out by the microbroth dilution technique in accordance with the Clinical and Laboratory Standards Institute (document M100-S17) using the disc diffusion method ${ }^{11}$ and a fully automated microbiology system (RAISUS; Nissui Pharmaceutical Co, Ltd, Tokyo, Japan).

The variables investigated were the conjunctival sac bacterial isolation rate, details of the bacterial isolates, and percentage of drug-resistant isolates, which were compared among age groups and according to the presence/absence of diabetes mellitus, hyperlipidemia, dialysis therapy, oral steroid use, usage of eye drops excluding antibacterial medicine, dry eye syndrome, or allergic conjunctivitis. Patients with dry eye syndrome were only enrolled in this study if they were receiving treatment with artificial tears or hyaluronic acid eye drops. Patients excluding dry eye syndrome were compared by the existence of usage of eye drops containing preservatives. Among patients with diabetes, the result was compared by the level of hemoglobin $\mathrm{A}_{1 \mathrm{c}}$.

Preoperative administration with levofloxacin (LVFX) eye drops for 3 days, which was evaluated in a multicenter study sponsored by the Japanese Association for Ocular Infection, ${ }^{12}$ was employed in this study routinely, and no oral antibacterial medicine was applied before cataract surgery. The patients were also treated routinely with faropenem sodium hydrate (Farom ${ }^{\circledR}$; Maruho, Tokyo, Japan) at a dose of $600 \mathrm{mg}$ daily for 4 days after cataract surgery.

Statistical analyses were performed using IBM SPSS for Windows (v 14.0; SPSS, Inc, Chicago, IL). The $2 \times 2$ Chi square test was employed for categorical comparison.

\section{Results}

None of the patients in this study contracted endophthalmitis after cataract surgery.

Bacteria were isolated from 227 (39.2\%) of the 579 eyes studied. Of these 227 eyes, a single isolate was detected in 179 eyes $(78.9 \%)$, while there were two isolates in 39 eyes $(17.2 \%)$, three isolates in eight eyes $(3.5 \%)$, and four isolates in one eye $(0.4 \%)$.

In more detail, there were 191 strains of Gram-positive cocci, accounting for $67.0 \%$ of all isolates, as well as 127 strains $(44.5 \%)$ of methicillin-sensitive coagulasenegative staphylococci, 37 strains (12.7\%) of methicillinresistant coagulase-negative staphylococci, eight strains (2.9\%) of methicillin-sensitive Staphylococcus aureus, and three strains $(1.0 \%)$ of methicillin-resistant $S$. aureus (Table 1). Among 76 Gram-positive bacilli isolates (26.7\%), all were of the genus Corynebacterium. There was only one Gram-negative coccus isolated $(0.4 \%)$, which was identified as Moraxella catarrhalis. There were 16 Gram-negative bacillary isolates (5.9\%), including three Escherichia coli isolates $(1.0 \%)$; two isolates $(0.7 \%)$ each of Pseudomonas aeruginosa, Acinetobacter spp, and nonglucose-fermenting bacteria; and one isolate (0.4\%) each of Proteus vulgaris, Proteus mirabilis, Enterobacter aerogenes, Serratia marcescens, Klebsiella oxytoca, and Alcaligenes spp.

The bacterial isolation rate was significantly lower for patients aged $\leq 60$ years compared with patients $61-70$ years, 
Table I Bacterial isolates and rates

\begin{tabular}{|c|c|c|}
\hline & Total & $\%$ \\
\hline Gram-positive cocci & 191 & $67.0 \%$ \\
\hline Staphylococcus epidermidis (MSCNS) & 127 & $44.5 \%$ \\
\hline Staphylococcus epidermidis (MRCNS) & 37 & $12.7 \%$ \\
\hline Staphylococcus aureus (MSSA) & 8 & $2.9 \%$ \\
\hline Staphylococcus aureus (MRSA) & 3 & $1.0 \%$ \\
\hline Enterococcus spp & 6 & $2.0 \%$ \\
\hline Enterococcus faecalis & 2 & $0.7 \%$ \\
\hline$\alpha$-Streptococcus & 6 & $2.0 \%$ \\
\hline Streptococcus equinus & I & $0.4 \%$ \\
\hline Streptococcus equisimilis & I & $0.4 \%$ \\
\hline Streptococcus pneumonia (PSSP) & I & $0.4 \%$ \\
\hline Gram-positive bacilli & 76 & $26.7 \%$ \\
\hline Corynebacterium spp & 76 & $26.7 \%$ \\
\hline Gram-negative cocci & I & $0.4 \%$ \\
\hline Moraxella catarrhalis & 1 & $0.4 \%$ \\
\hline Gram-negative bacilli & 16 & $5.9 \%$ \\
\hline Escherichia coli & 3 & $1.0 \%$ \\
\hline Pseudomonas aeruginosa & 2 & $0.7 \%$ \\
\hline Acinetobacter spp & 2 & $0.7 \%$ \\
\hline Nonglucose-fermenting bacteria & 2 & $0.7 \%$ \\
\hline Proteus vulgaris & I & $0.4 \%$ \\
\hline Proteus mirabilis & I & $0.4 \%$ \\
\hline Enterobacter aerogenes & I & $0.4 \%$ \\
\hline Serratia marcescens & I & $0.4 \%$ \\
\hline Klebsiella oxytoca & 1 & $0.4 \%$ \\
\hline Alcaligenes spp & I & $0.4 \%$ \\
\hline Haemophilus influenzae & 1 & $0.4 \%$ \\
\hline
\end{tabular}

Abbreviations: MRCNS, methicillin-resistant coagulase-negative staphylococci; MSCNS, methicillin-sensitive coagulase-negative staphylococci; MRSA, methicillinresistant Staphylococcus aureus; MSSA, methicillin-sensitive Staphylococcus aureus; PSSP, penicillin-susceptible Streptococcus pneumonia.

$71-80$ years, and $\geq 81$ years old $(P<0.001$; Table 2$)$. The bacterial isolation rate did not differ significantly between diabetics and nondiabetics (Table 3 ). There was also no significant difference in bacterial isolation rate in relation to presence/absence of diabetic retinopathy and hemoglobin $A_{1 c}$ level (Tables 3 and 4). No statistically significant differences were noted in relation to the presence/absence of dialysis therapy, oral steroid use, or allergic conjunctivitis (Table 3 ). In relation to whether the patients were using eye drops or not, the bacterial isolation rate was significantly lower $(P<0.001)$ for the group using eye drops $(85 / 275$ eyes, $30.9 \%$ ) than for the group not using such medication (142/304 eyes, 46.7\%). The bacterial isolation rate was

Table 2 Bacterial detection rate dependent on age

\begin{tabular}{ll}
\hline Age (years) & Culture positive/total (\%) \\
\hline$\leq 60$ & $12 / 73(16.4 \%)$ \\
$61-70$ & $72 / 177(40.7 \%)$ \\
$71-80$ & $91 / 228(39.9 \%)$ \\
$\geq 81$ & $52 / 101(51.5 \%)$ \\
\hline
\end{tabular}

Note: $2 \times 2$ Chi square test.
Table 3 Bacterial detection rate dependent on background

\begin{tabular}{lll}
\hline & \multicolumn{2}{l}{ Culture positive/total (\%) } \\
\cline { 2 - 3 } & Presence & Absence \\
\hline Diabetes mellitus & $72 / 198(36.4 \%)$ & $155 / 38 \mid(40.7 \%)$ \\
Diabetic retinopathy & $17 / 48(35.4 \%)$ & $12 / 33(36.4 \%)$ \\
Dialysis & $4 / 11(36.4 \%)$ & $223 / 568(39.3 \%)$ \\
Hyperlipidemia & $55 / 169(32.5 \%)$ & $172 / 410(42.0 \%)^{*}$ \\
Steroid therapy & $7 / 16(43.8 \%)$ & $220 / 563(39.1 \%)$ \\
Dry eye syndrome & $19 / 96(19.8 \%)$ & $208 / 483(43.1 \%)^{* *}$ \\
Usage of any eye drops & $85 / 275(30.9 \%)$ & $142 / 304(46.7 \%)^{* *}$ \\
Allergic conjunctivitis & $3 / 9(33.3 \%)$ & $224 / 570(39.3 \%)$ \\
\hline
\end{tabular}

Notes: $* P<0.05 ; * * P<0.001,2 \times 2$ Chi square test.

significantly lower $(P<0.001)$ for patients with dry eye syndrome $(19 / 96,19.8 \%)$ than for those without it (208/483, 43.1\%). A significantly lower $(P<0.05)$ bacterial isolation rate was also noted for patients with hyperlipidemia $(55 / 169$, $32.5 \%)$ than for those without it (172/410, 42.0\%).

For methicillin-resistant coagulase-negative staphylococci, the percentage of resistant organisms was significantly greater $(P<0.05)$ in diabetic patients (13 strains, $20.3 \%)$ than in nondiabetic patients (eight strains, $7.0 \%$ ).

Of the 285 strains isolated, 40 strains $(14.0 \%)$ were resistant to LVFX. For cefmenoxime, 39 (15.2\%) out of 257 strains were resistant, while $42(17.9 \%)$ out of 262 strains were resistant to tobramycin. The percentage of resistant organisms did not differ significantly among these antimicrobial agents. Resistance to all three of these drugs was demonstrated by six methicillin-resistant coagulasenegative staphylococci strains, two enterococcal strains, and one methicillin-resistant $S$. aureus (Figure 1).

\section{Discussion}

Endophthalmitis after cataract surgery is a severe complication that can occur no matter how strictly the sterility of the operative field is maintained and despite aseptic surgical manipulations/instruments. Risk factors in the surgical procedures and background of the patients are as previously

Table 4 Bacterial detection rate dependent on hemoglobin $A_{I c}$ level

\begin{tabular}{ll}
\hline Hemoglobin A $\mathbf{I c}_{\mathrm{Ic}}$ level & Culture positive/total (\%) \\
\hline$<6$ & $38 / 100(38.0 \%)$ \\
$\geq 6$ & $33 / 97(34.0 \%)$ \\
$<7$ & $50 / 139(36.0 \%)$ \\
$\geq 7$ & $21 / 58(36.2 \%)$ \\
$<8$ & $62 / 170(36.5 \%)$ \\
$\geq 8$ & $9 / 27(33.3 \%)$ \\
$<9$ & $67 / 181(37.0 \%)$ \\
$\geq 9$ & $4 / 16(25.0 \%)$ \\
\hline
\end{tabular}




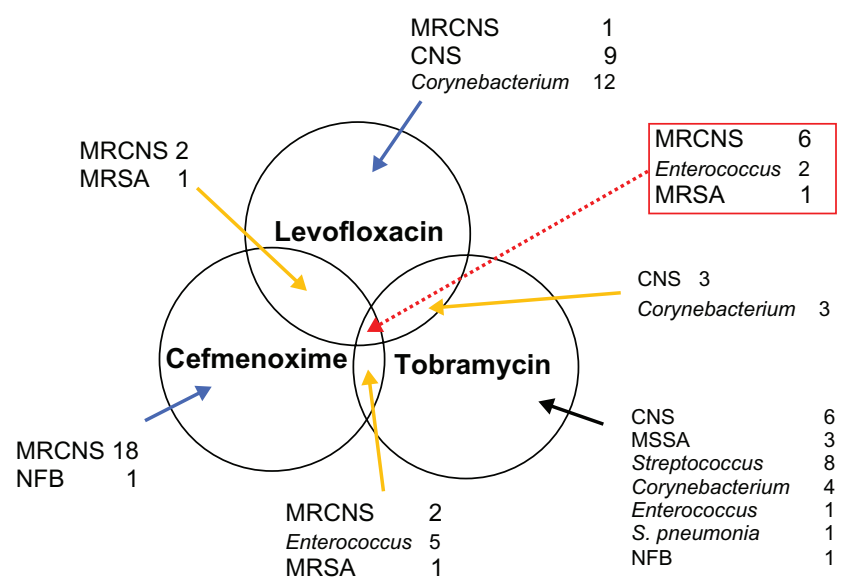

Figure I Resistance to levofloxacin, cefmenoxime, and tobramycin was shown in six methicillin-resistant coagulase-negative staphylococci strains, two enterococcal strains, and one methicillin-resistant Staphylococcus aureus strain.

Abbreviations: CNS, coagulase-negative staphylococci; MRCNS, methicillin-resistant coagulase-negative staphylococci; MRSA, methicillin-resistant Staphylococcus aureus; MSSA, methicillin-sensitive Staphylococcus aureus; NFB, nonglucose-fermenting bacteria.

reported, for example, in men, aged patients, and those with capsular rupture, a prior diagnosis of proliferative diabetic retinopathy, and cataract surgery combined with another intraocular surgical procedure on the same day. ${ }^{13,14}$ Great importance is attached to preventive measures for this complication. Evidence-based prophylactic measures for postcataract surgery endophthalmitis include preoperative instillation of povidone-iodine eye drops as described by Ciulla et $\mathrm{al}^{15}$ and 3-day preoperative sterilization with LVFX eye drops, which was evaluated in a multicenter study sponsored by the Japanese Association for Ocular Infection. ${ }^{12}$ The pathogens causing endophthalmitis are mainly indigenous bacteria from sites on the ocular surface such as the conjunctival sac, eyelids, and meibomian glands. These microorganisms can be diminished by disinfection, but it is impossible to completely eradicate them even by the strongest disinfection protocol. Microorganisms that are resistant to disinfectants or antimicrobial agents may also be encountered. Although the evidence-based measures that have been demonstrated to be effective for prevention of endophthalmitis after cataract surgery are favorably regarded, it would seem likely that uniform employment of such measures could entail some risk. Therefore, the present study was undertaken to identify significant risk factors.

It is generally agreed that administration of corticosteroids, diabetes mellitus, and old age, which reduce immunity, are associated with a higher bacterial detection rate. ${ }^{4-8}$ In the present series, however, old age was the only factor associated with a statistically higher bacterial detection rate and no significant difference in bacterial detection was noted in relation to the presence/absence of steroid therapy or diabetes. Furthermore, there was no significant difference in bacterial detection rate among diabetic patients in relation to hemoglobin $A_{1 c}$, diabetic retinopathy, or glycosuria. The reason for this is unclear, but it is possible that these factors have little influence on the microbial flora in the conjunctival sac. Microorganisms isolated from the eye, especially from parts of the ocular surface such as the conjunctiva and cornea, are in direct contact with the external environment and are thought to originate from the palpebral skin influenced by the general condition as well as the meibomian glands and oral indigenous flora. Therefore, these multiple origins could be a reason.

It was found that hyperlipidemia, dry eye syndrome, and use of other topical ocular medication were associated with significantly lower bacterial detection rates. It has been reported that hypercholesterolemia leads to changes in the composition of nasolacrimal duct fluid, so it is possible that such changes may affect the conjunctival sac and its bacterial flora, which are located upstream of the nasolacrimal duct, ${ }^{16}$ although the precise mechanism is yet to be clarified. Regarding dry eye syndrome, only patients who were using artificial tears or hyaluronic acid eye drops were enrolled, and they showed a lower bacterial detection rate as did the patients using other types of eye drops. Honda et al compared bacterial isolation rates from the conjunctival sac between patients receiving topical medication for glaucoma and those not receiving such medication. ${ }^{10}$ Bacterial detection rate was $40.3 \%$ in the topical medication group, which was significantly lower than the rate of $67.8 \%$ in the group without topical medication $(P<0.05$, Fisher's test). These results were similar to the present findings and a washout effect of eye drops may be involved. On the other hand, Hori et al reported that the percentage of LVFX-resistant isolates obtained from the conjunctival sac was higher in patients who had dry eye syndrome compared with healthy subjects. ${ }^{17}$ They stated that it remains unclear whether fragility of the ocular surface in patients with this syndrome or bacterial contamination of the eyelids and fingers due to application of topical medication is responsible for this finding. Although no such difference in the percentage of LVFX-resistant microorganisms was obtained in the present study (data not shown), this possibility should be kept in mind.

It has been documented that bacteria isolated from the conjunctival sac in healthy persons are usually nonpathogenic, with $S$. epidermidis being found frequently, which is part of the indigenous skin flora. ${ }^{18}$ Coagulasenegative staphylococci was the most frequent isolate in the 
present investigation as well. The isolation rate of methicillinresistant coagulase-negative staphylococci among coagulasenegative staphylococci was significantly higher in patients with diabetes mellitus than in nondiabetic patients. Possible reasons for this include a compromised immune status due to diabetes, diabetic infections, use of antimicrobial drugs, and opportunistic infections. This also points to the importance of maintaining caution about bacterial drug resistance even if microorganisms are not virulent. Increased drug resistance rates have been pointed out for Corynebacterium spp. ${ }^{19}$

There is some apprehension regarding an increase of microbial drug resistance due to widespread use of LVFX eye drops. The drug resistance rate increases progressively along with increased use of such eye drops. It is recommended in Japan to administer LVFX eye drops from 3 days before cataract surgery for prevention of postoperative endophthalmitis. ${ }^{15}$ In the present study, this protocol was followed in all patients, and no oral antibacterial medicine was administered before cataract surgery.

However, indiscriminate use of LVFX could not only lead to masking of resistant microorganisms but could also result in the potential risk of causing an increase in drug resistance. Therefore, attention should be paid to the possible presence of resistant microorganisms especially in elderly patients and patients with dry eye syndrome like those with higher bacterial isolation rates in this study. The same caution should be exercised for diabetic patients since multidrugresistant isolates with resistance to LVFX, cefmenoxime, and tobramycin were more frequent among diabetics in the present study.

\section{Disclosure}

The authors report no conflicts of interest in this work.

\section{References}

1. Resnikoff S, Pascolini D, Etya'ale D, et al. Global data on visual impairment in the year 2002. Bull World Health Organ. 2004;82(11):844-851.

2. Oshika T, Hatano H, Kuwayama Y, et al. Incidence of endophthalmitis after cataract surgery in Japan. Acta Ophthalmol Scand. 2007;85(8): $848-851$.
3. Speaker MG, Milch FA, Shah MK, Eisner W, Kreiswirth BN. Role of external bacterial flora in the pathogenesis of acute postoperative endophthalmitis. Ophthalmology. 1991;98(5):639-649.

4. Kattan HM, Flynn HW Jr, Pflugfelder SC, Robertson C, Forster RK. Nosocomial endophthalmitis survey. Current incidence of infection after intraocular surgery. Ophthalmology. 1991;98(2):227-238.

5. Phillips WB 2nd, Tasman WS. Postoperative endophthalmitis in association with diabetes mellitus. Ophthalmology. 1994;101(3): 508-518.

6. Kurokawa N, Hayashi K, Konishi M, Yamada M, Noda T, Mashima Y. Increasing ofloxacin resistance of bacterial flora from conjunctival sac of preoperative ophthalmic patients in Japan. Jpn J Ophthalmol. 2002;46(5):586-589.

7. Miller B, Ellis PP. Conjunctival flora in patients receiving immunosuppressive drugs. Arch Ophthalmol. 1977;95(11):2012-2014.

8. Allen HF. Prevention of postoperative endophthalmitis. Ophthalmology. 1978;85(4):386-389.

9. Toshida H, Kogure N, Inoue N, Murakami A. Trends in microbial keratitis in Japan. Eye Contact Lens. 2007;33(2):70-73.

10. Honda R, Toshida H, Suto C, et al. Effect of long-term treatment with eye drops for glaucoma on conjunctival bacterial flora. Infect Drug Resist. 2011;4:191-196.

11. Clinical and Laboratory Standards Institute. Performance Standards for Antimicrobial Susceptibility Testing; Seventeenth Informational Supplement (M100-S17). Wayne, PA: Clinical and Laboratory Standards Institute; 2007.

12. Inoue Y, Usui M, Ohashi Y, Shiota H, Yamazaki T; Preoperative Disinfection Study Group. Preoperative disinfection of the conjunctival sac with antibiotics and iodine compounds: a prospective randomized multicenter study. Jpn J Ophthalmol. 2008;52(3):151-161.

13. Hatch WV, Cernat G, Wong D, Devenyi R, Bell CM. Risk factors for acute endophthalmitis after cataract surgery: a population-based study. Ophthalmology. 2009;116(3):425-430.

14. Stein JD, Grossman DS, Mundy KM, Sugar A, Sloan FA. Severe adverse events after cataract surgery among medicare beneficiaries. Ophthalmology. 2011;118(9):1716-1723.

15. Ciulla TA, Starr MB, Masket S. Bacterial endophthalmitis prophylaxis for cataract surgery: an evidence-based update. Ophthalmology. 2002; 109(1):13-24.

16. Marini RP, Foltz CJ, Kersten D, Batchelder M, Kaser W, Li X. Microbiologic, radiographic, and anatomic study of the nasolacrimal duct apparatus in the rabbit (Oryctolagus cuniculus). Lab Anim Sci. 1996;46(6):656-662.

17. Hori Y, Maeda N, Sakamoto M, Koh S, Inoue T, Tano Y. Bacteriologic profile of the conjunctiva in the patients with dry eye. Am J Ophthalmol. 2008;146(5):729-734.

18. McNatt J, Allen SD, Wilson LA, Dowell VR Jr. Anaerobic flora of the normal human conjunctival sac. Arch Ophthalmol. 1978; 96(8):1448-1450.

19. Eguchi H, Kuwahara T, Miyamoto T, et al. High-level fluoroquinolone resistance in ophthalmic clinical isolates belonging to the species Corynebacterium macginleyi. J Clin Microbiol. 2008;46(2):527-532.
Infection and Drug Resistance

\section{Publish your work in this journal}

Infection and Drug Resistance is an international, peer-reviewed openaccess journal that focuses on the optimal treatment of infection (bacterial, fungal and viral) and the development and institution of preventive strategies to minimize the development and spread of resistance. The journal is specifically concerned with the epidemiology of antibiotic

\section{Dovepress}

resistance and the mechanisms of resistance development and diffusion in both hospitals and the community. The manuscript management system is completely online and includes a very quick and fair peerreview system, which is all easy to use. Visit http://www.dovepress.com/ testimonials.php to read real quotes from published authors. 